\title{
Tang Hanedanlığı Dönemi Çin Şiiri, Wang Wei ve Meng Haoran'ın“Beş İmli Dört Mısralı Şiir (五言绝句)” Özelliğine Göre Yazılmış Şiirleri Üzerine Bir İnceleme*
}

\author{
DR. ÖĞR. ÜYESİ NURAY PAMUK ÖZTÜRK*
}

Öz

Çin toprakları tarih boyunca birçok hanedanlığa ev sahipliği yapmıştır. Bu hanedanlıklardan biri de Tang Hanedanlığıdır (618-906). Tang Hanedanlığının kurulması ile Çin'de yeni bir dönem başlamıştır. Bu dönemde siyasi, ekonomik, sosyal ve kültürel alanda birçok gelişme yaşanmıştır. Kültürel alanda yaşanan gelişmelerin içerisinde edebiyat önemli bir yere sahiptir. Bu dönem, Çin edebiyatının gelişmesinde ve yenilenmesinde bir dönüm noktası niteliğindedir. Tang Hanedanlığı döneminde ortaya çıarılan edebiyat eserleri, günümüz Çin edebiyat eserlerinin temelinin oluşmasında büyük etkiye sahiptir. Sanat ve edebiyata önem veren imparatorların desteği ile gelişen Tang dönemi edebiyatında en göze çarpan ögelerden biri şiirdir. Daha önceki dönemlerde şairler tarafından imparatora ve saraya övgüler sunan şiirler yazılırken, Tang Hanedanllğ̆ döneminde şiirlerde genel olarak; halkın durumu, doğa olayları, sosyal yaşam, savaşlar, kahramanlıklar, sevgi gibi konular ele alınmıştır. Şiirler yapısal olarak beş veya yedi im kullanılarak yazılmıştır. Bu çalışmada Tang Hanedanlığı döneminin Beş İmli Dört Mısralı Şiir türünün özelliklerinden, şair Wang Wei (701-761) ve Meng Haoran'ın (689-740) hayatlarından bahsedilmiştir. Şairlerin beş imli dört mısralı şiirlerine örnekler verilmiştir. Şiirlerin Türkçe anlatıma en uygun şekilde çevirileri yapılmaya çalışılmış olup konuları hakkında inceleme yapılmıştır.

Anahtar sözcükler: Tang Hanedanlığı, Tang Şiiri, Wang Wei, Meng Haoran, Beş İmli Şiir

A STUDY ON CHINESE POETRY OF TANG ERA AND “THE FIVE CHARACTER QUATRAIN (五言绝句)” OF WANG WEI AND MENG HAORAN

\section{Abstract}

China has been home for many dynasties in the history. One of them was Tang Dynasty (618-906). A new era started in China with the foundation of Tang Dynasty. There had been a lot of developments in the political, economic, social and cultural areas during this era. Literature had an important place in cultural developments. This era was a turning point in the development of

\footnotetext{
* Bu makale, 07-09 Kasım 2018 tarihinde Karamanoğlu Mehmetbey Üniversitesi tarafından düzenlenen I. Karaman Dil ve Edebiyat Kongresinde sunulan ve özet olarak yayınlanan bildirinin genişletilmiş şeklidir.

* Selçuk Ün. YDY Mütercim Tercümanlık Böl. nuray_panuk@hotmail.com, orcid: 0000-0001-8186-8116 
Chinese literature. The works of the Tang Dynasty have had a great impact on the foundation of contemporary Chinese literature. One of the most outstanding item of the Tang period literature, developed with the support of the emperors, was poetry. In earlier periods, the subjects of the poems were praises about the emperor and his dynasty, but in Tang Dynasty it was changed to the situation of the nation, social life, wars, heroism, love etc. Poems were written using Five Chinese Character Style or Seven Chinese Character Style. In this article we mention about The Five Character Quatrain, the biography of Wang Wei (701-761) and Meng Haoran (689-740) and give examples from their Five Chinese Character Style poetry. We tried to translate the poems in the most appropriate way to the Turkish narration and the subjects have been examined.

Keywords: Tang Dynasty, Tang Poetry, Wang Wei, Meng Haoran, The Five Character Quatrain

\section{Gİiș}

in topraklarında yaklaşık dört yüz yıl hüküm süren Han Hanedanlığı (kuruluş M.Ö. 206), 220 yılında yıkılmıştır. Hanedanlığın yıkılmasından sonra, uzun yıllar sürecek bir kargaşa dönemi başlamıştır. Bu döneme, Wei-Jin Güney Kuzey Hanedanlıkları ${ }^{1}$ dönemi denilmektedir. 220 yılında başlayan bu dağılma ve kargaşa dönemi, 581 yılında Sui Hanedanlığının kurulması ile son bulmuştur. Ancak Sui Hanedanlığı dönemi de fazla uzun sürmemiştir. Otuz yedi yıl hüküm süren Hanedanlık, 618 yılında yıkılmıştır. Bütün bu ayaklanmaların, savaşların ve benzeri olayların yaşandığı dönemde edebiyat ve sanattaki gelişme, ilerleme ve yenilenme çok kısıtlı olmuştur. Edebiyat ve sanat, merkezi otoritenin kontrolünde kalmıştır. Bu süreçte genel olarak soyluları, saray hayatını ve imparatoru öven eserler ortaya konulmuştur (Luo, 2011, s. 391-393).

Tang Hanedanlığı, 618-906 yılları arasında başta Çin toprakları olmak üzere geniş bir coğrafyada hüküm sürmüştür. Hanedanlığın kurucusu Li Yuan (李渊)'dir. Li Yuan, imparator olduktan sonra Tang Gaozu (唐高祖 618-626) adını almıştır. Hanedanlığın başkenti Chang-an şehridir ${ }^{2}$. Chang-an şehrinin Tang Hanedanlığının zenginliğini yansıttı̆̆ından bahsedilmektedir. Hanedanlık döneminde, Chang-an'da yapılan inşa çalışmalarının günümüze kadar gelen eserlerin ortaya konulması bakımından çok önemli olduğu aktarılmaktadır (Taşağıl, 2017, s. 138). Bu dönemde ekonomik, siyasi, kültürel, edebi alanda ve dış ilişkiler alanında birçok gelişme

\footnotetext{
${ }^{1}$ Han Hanedanlığının dağılmasının ardından birçok göçebe ulus Çin'in kuzey bölgesine yerleşmiştir. Dağınık şekilde gelen bu boylar zamanla irili ufaklı siyasi birlikler oluşturmuştur. Çok sayıda siyasi birliğin kurulduğu bu dönem WeiJin Güney Kuzey Hanedanlıkları (魏晋南北朝Wèi Jìn Nán Běi Cháo) dönemi olarak adlandırılmaktadır. Wei-Jin Güney Kuzey Hanedanlıkları; Doğu Han Hanedanlığının ardından, Çin'de Üç Krallık (220-280), Cao-Wei (220-266), Shu (221-263), Wu (222-280) döneminden 581 yılında kurulan Sui (隋) Hanedanlığına kadar olan dönemin adıdır. Güney Hanedanlıkları; Liu-Song (420-479), Qi (479-502), Liang (502-557), Chen (557-589), Son Liang (555-587), Kuzey Hanedanlıkları; Kuzey Wei (386-534), Doğu Wei (534-550), Batı Wei (535-556), Kuzey Qi (550-577), Kuzey Zhou (557-581)" dur (Aktaş, 2017, s. 285-300).

2 Tang Hanedanlığının kuruluşu ile ilgili ayrıntılı bilgi için bkz. (Hung, Li Shi Min, Founding The Tang Dynasty The Strategies That Made China The Greatest Empire In Asia, 2013)
} 
yaşanmıştır. Bütün bu gelişmeler, Hanedanlık içerisinde bir refah ortamı oluşmasını sağlamıştır. Oluşan refah ortamı, edebiyat alanında da gelişmelerin hızlanmasına zemin hazırlamıştır.

Çin tarihinin her döneminde, edebiyat ve sanat alanında çalışmalar yapılmıştır. Ancak Tang Hanedanlığ 1 döneminde edebiyat ve sanat en parlak dönemini yaşamıştır. Modern Çin Edebiyatı ${ }^{3}$ eserlerini dahi etkileyecek nitelikte eserler ortaya konulmuştur. Bu dönemde edebiyat alanında yaşanan gelişmelerde en öne çıan edebi tür şiirdir. Çin şiiri, Tang Hanedanlığı döneminde, o tarihe kadar varabileceği en üst seviyeye ulaşmıştır ve bu dönemde birçok başarılı şair yetişmiştir.

Hükümet kademesi, edebiyat ve özellikle şiirde yaşanan gelişmelere büyük destek olmuştur. Kendisinin de şiir yazabildiği aktarılan İmparator Tang Taizong'un (唐太宗), hükümdarlığ döneminde edebiyat eserlerini derlettiği, büyük bir kütüphane kurdurduğu, şiir yazabilen memurları üst kademelerde görevlendirdiği ve ödüller verdiği aktarılmaktadır (Xu, 2003, s. 315).

Tang Hanedanlığı öncesi dönemlere bakıldığında, edebiyatta çoğunlukla imparatora ve hanedanlığa övgüler sunan eserler ortaya konulmuştur. Özellikle üçüncü ve altıncı yüzyılların edebiyat eserleri, Prof. Dr. Eberhard'ın tabiri ile saraylarda bilginler arasında oyuncak olmuştur. Eserlerde hislerin derinliğinden ziyade şeklin mükemmeliyeti ön planda tutulmuştur (Eberhard, 1995, s. 220). Ancak Tang Hanedanlığı döneminde edebiyat halk arasına karışmış; soyluların hayatları, imparatora ve saraya övgü, aşk, özlem konulu şiirlerin yanı sıra doğa olayları, savaşlar, yalnızlık, kahramanlıklar, halkın durumu ve sosyal yaşamı, memleket hasreti hakkında da birçok şiir yazılmıştır. Şiirler, daha önceki dönemlerin görselliğinin etkisi altında kalmıştır. Ancak şairler, önceki dönemlerin şekilselliği ile ortaya koydukları eserleri, gerçek hislerle doldurmuşlardır. Soylu kesimden gelen şairlerin yanı sıra halk arasından da başarılı şairler yetişmiştir. Tang dönemi Çin şiiri, bu yetenekli şairler sayesinde hem nitelik bakımından çeşitlenmiş ve gelişmiş hem de sayı bakımından artış göstermiştir (Zhu, 2011, s. 310) (Eberhard, 1995, s. 220-221) (Luo, 2011, s. 194202).

Şiirdeki bu çeşitliliğin sebeplerinden biri olarak hanedanlığın sınırlarının genişlemesi gösterilebilir. Sınırları genişleyen hanedanlık birçok etnik grubu yönetimi altına almıştır. Bu durum çok uluslu bir toplum yapısı oluşmasını sağlamıştır. Çok uluslu toplum yapısı da, kültürel

\footnotetext{
${ }^{3}$ Modern Çin Edebiyatı: “Çin'de “4 Mayıs Hareketi” Modern Çin Edebiyatının başlangıcı olarak kabul edilmektedir. Bu süreçte atılan en büyük adım, edebiyat dilinde yapılan sadeleşme hareketidir. Buna göre; klasik edebiyatın yazı dili olan “wenyan” den ( 文言), günlük konuşma dili olan “baihua” ya (白话) geçiş yapılmıştır. Edebiyat sadece soylu ve aydın kesimin anlayabileceği eserler veren bir alan olmaktan sıyrılarak halka ulaşmıştır" (Ünal Chiang, Çin Modern Edebiyatı Deneme Eserleri Seçkisi, 2016, s. 11-16). Modern Çin Edebiyatının başlangıcı kabul edilen 4 Mayıs Hareketi ile ilgili olarak ayrıca şöyle söylenmektedir: “4 Mayıs döneminin edebiyat devrimcileri, feodalizm ve klasik dil karşıtı görüşleri ve yenilikçi fikirleri ile birlik sağlamış olsalar da; eser verme ve eserlerine seçtikleri konular açısından iki farklı ekole ayrılmışlardır. “Edebiyat Araştırmaları Topluluğu” ( 文學研究會) ve “Yaratıcı Toplum” (創造社) adlarıyla kurulan bu iki ekolün izledikleri yol farklı olsa da, feodalist edebiyata karşı duruşları ve modern edebiyat eğilimleri temelde aynıydı. "Edebiyat Araştırmaları Topluluğu” temelde halk için edebiyat görüşünü savunan ve teknik açıdan toplum gerçeklerini, insanın gerçek hislerini yazmayı hedefleyen bir topluluktu. Bu topluluğun genel bakış açısına göre; edebiyat halk ile iç içe ve halk için yapılmalıydı. Bu sebeple; bir eserin içeriğini toplumsal bir tema oluşturmalıydı. Edebi eserler, insanların etrafında gelişen önemsiz olaylar üzerine değil, hayatını zor şartlarda kazanan halkın toplumsal gerçekleri üzerine yazılmalıydı." (Ünal Chiang, 4 Mayıs Hareketi Ve Çin Edebiyatında Modernleşme: Modern Çin Edebiyatının Öncüsü Zhu Ziqing Ve Unutulmaz Eseri “Beiying”, 2017, s. 41-58)
} 
zenginliği ve çeşitliliği beraberinde getirmiştir. Bu zenginlik ve çeşitlilik, haliyle edebiyat eserlerine de yansımıştır.

Bu dönemde çoğunlukla bir mısrası beş veya yedi im den oluşan şiirler yazılmıştır. Şiirlerin uzunluğu konunun işlenişine göre değişmekle birlikte genellikle dörtlükler halinde uyaklıdır. Günümüzde Tang dönemi Çin şiiri “en az im ile en fazla olanı anlatma sanatı” olarak nitelendirilmektedir (Xing, 1976, s. 45). Mısrayı oluşturan imler cümle yapısı bakımından birbirinden bağımsızdır. Şiirde kişi ve mekân geri planda tutularak, durum ve olay ön plana çıkarılmaktadır. Doç. Dr. Kırilen, Tang şiirinde beş veya yedi im ile geniş bir anlam yakalama konusunda şu bilgiyi vermektedir; “... Böylece imgelerle pastoral bir mekân oluşturulur ve sahneyi kuran sembolik parçalar bu mekânda devindirilir. Çince sözcükler, canlı ve sözdizimsel bakımdan birbirinden bağımsız simgelerdir. Bu yüzden şiirde çoğunlukla zaman ve bakı belirsizdir; özne geri planda tutulur ve hareketler ve olay ön plana çlkarılır." (Kırilen, 2010) .

Şiirler yapılarına, uzunluklarına ve uyaklarına göre farklı isimlerle adlandırılmaktadır. Bunlar; Beş İmli Klasik Şiir (无言古诗-Wú Yán Gǔshī), Yedi İmli Klasik Şiir (七言古诗-Qī Yán Gǔshī), Beş İmli Sekiz Mısralı Şiir(五言律诗- Wǔ Yán Lùshī), Yedi İmli Sekiz Mısralı Şiir (七言律诗Qī Yán Lù̀sh̄̄), Beş İmli Dört Misralı Şiir (五言绝句- Wǔ Yán Juégōu), Yedi İmli Dört Misralı Şiir'dir (七言绝句- Qī Yán Juégōu) (Pamuk Öztürk, 2016, s. 79-85) (Qing, 2009, s. 1-6).

\section{Beş İmli Dört Mısralı Şiir (五言绝句)}

Beş İmli Dört Mısralı Şiire “Beşli Dörtlük (五绝)” de denilmektedir. Bu şiir türü, Tang Hanedanlığı döneminde yaşanan gelişmelere bağlı olarak "modern tarzda yazılmış şiir" sınıfına girmekte iken günümüzde klasik Çin şiiri türlerinden biridir. Beş İmli Dört Mısralı Şiir özelliğine göre yazılmış şiirlerin tarihi, Han Hanedanlığı dönemine kadar uzanmaktadır. Güney Hanedanlıkları dönemi yazarlarından Xu Ling'in (徐陵) $)^{5}$ “Yu Tai Xin Yong (玉台新咏)”6 derlemesinde bulunan dört misralı eserler, Beş İmli Dört Mısralı Şiir özelliğine göre yazılmış şiirlerin ilk örnekleri olarak kabul edilmektedir (Qing, 2009, s. 285).

Beş İmli Dört Mısralı Şiirlerde birinci, ikinci ve dördüncü mısralar, bazılarında ise ikinci ve dördüncü mısralar uyaklıdır. Daha önceki dönemlerde aynı özellikte yazılan şiirlerin aksine Tang döneminde ortaya konulan Beş İmli Dört Mısralı Şiirlerde anlatım yalın ve açıktır. Sadece soylu ve eğitimli kesimin değil halkın da şiirleri anlamasını kolaylaştırmak amacıyla anlatımda sadeliğe önem verilmiştir. Bu durum şiirlerin daha geniş kitlelere ulaşmasına yardımcı olmuştur. Tang Hanedanlığı döneminin Beş İmli Dört Mısralı Şiir türünün önde gelen şairleri Li Bai (李白), Wang

\footnotetext{
${ }^{4}$ İm: Çince karakterleri ifade etmek için kullanılır. Her bir karakter bir im'dir.

5 Xu Ling (徐陵), 507-583 yılları arasında günümüz Shandong bölgesi olarak adlandırılan bölgede yaşamış bir edebiyatçıdır.

${ }^{6}$ Yu Tai Xin Yong (玉台新咏): Han Hanedanlığı döneminden Güney Liang Hanedanlığı dönemine kadar yazılan şiirlerin bulunduğu bir şiir derlemesidir. 6. Yüzyılda Xu Ling tarafından derlenmeye başlanmıştır ve içerisinde toplamda 690 şiir bulunmaktadır. Günümüzde Zhang Lihua tarafından tekrar revize edilmiştir.
} 
Wei (王维), Meng Haoran (孟浩然) ve Liu Zhangqing'dir (刘长青, 727-790). Wang Wei (王维) ve Meng Haoran (孟浩然), doğa olayları ve kırsal kesimde yaşam temalı şiirlerde önde gelen isimlerdir. Ayrıca bu iki şair Wang Meng Şiir Okulu'nun kurucularıdır. Bu okul, Tang döneminde birçok şairin yetişmesinde önemli rol oynamıştır. Bu sebeple Wang Wei ve Men Haoran çalışmanın odak noktası olarak belirlenmiştir. Çalışmada şairlerin doğa olaylarını konu aldıkları ve Beş İmli Dört Mısralı Şiir özelliğine göre yazdıkları şiirlerinden örnekler incelenmiştir.

\section{Wang Wei (王维)}

Wang Wei'in 701 yılında Taiyuan bölgesinin Qixian şehrinde doğduğu (Günümüz Shanxi Bölgesi Jinzhong şehri) ve sonrasında ailesiyle birlikte Puzhou'ya (Günümüz Shanxi Bölgesi Yuncheng şehri) gittiği aktarılmaktadır. Wang Wei, Tang Hanedanlığı kültürel gelişmelerinin en fazla olduğu dönemde yaşamıştır. Bu durum onun sanatsal kişiliğine yansımıştır. Budist bir aileye mensup olan Wang Wei, annesinden etkilenerek Budizm öğretisini benimsemiştir. Düşünce tarzında ve eserlerinde bu öğretinin etkileri olduğu düşünülmektedir. 721 yılında imparatorluk sınavını kazanarak memur olan Wang Wei, devlet adamı ve şair olmasının yanı sıra, başarılı bir yazar, ressam ve müzisyendir (Qing, 2009, s. 16) (Sun, 2007, s. 132-133) (Luo, 2011, s. 287). Sanatın bu kadar çok dalıyla ilgilenmesinin, şiirlerinde çeşitliliğe neden olduğu söylenebilir.

Wang Wei 761 yılında öldüğünde ardında birçok eser bırakmıştır. Tang Hanedanlığı imparatorlarından Tang Daizong (唐代宗)'un Wang Wei'in eserlerinin derlenmesini emretmesi, onun siyasi ve edebi kişiliğinde ne kadar başarılı olduğunun göstergesidir. İmparatorun emrini yerine getiren dönemin edebiyatçıları, on ciltten oluşan Wang Wei Antolojisi'ni (王维集) hazırlamışlardır (Qing, 2009, s. 16).

Wang Wei'in yaşamı boyunca 400'den fazla şiir yazdığ tahmin edilmektedir. Bahsedilen antolojiler ve derlemeler sayesinde şiirlerinin büyük bir bölümü korunarak günümüze kadar ulaşabilmiştir. Wang Wei, on beş yaşında şiir yazmaya başlamıştır ve beş imden oluşan şiirleri çoğunluktadır. Fakat onu temsil eden doğa olayları temalı şiirlerini ileri yaşlarında kaleme almıştır (Sun, 2007, s. 229-230). Şairin eserleri arasında Beş İmli Dört Mısralı Şiir türüne göre yazılmış ve doğa olayları temalı şiirlerinin en güzel örnekleri şunlardır;

\section{Hasret Çekmek}

Kırmızı fasulyeler güneyde ekilir,

Bahar gelince kaç tanesi yetişir?

Ne kadarmı hasat edersen,

Ürünler kadar hasret çekilir.
相思

红豆生南国,

春来发几枝?

愿君多采撷,

此物最相思。 
Kırmızı fasulyenin ${ }^{7}$ bir diğer adı hatıra/hasret tohumudur. Kelimenin Çince karşılığı Xiangsi zi' dır (相思子). Şiirin başlığ 1 olan Xiangsi (相思); hasret çekmek, burnunda tütmek anlamına gelmektedir. Kırmızı fasulye ve hasret çekmek kelimeleri arasında Çince fonetik bakımdan ilgi kurulmuştur. Wang Wei, şiirinde kırmızı fasulyenin hatıra tohumu anlamından yola çıarak arkadaşlarına duyduğu hasreti anlatmaktadır.

Wang Wei, Hasret Çekmek başlıklı şiirinde şunu dile getirmektedir; Kırmızı fasulyeler uzaklarda, güneyde yetişir. Siz şimdi orada yaşamaktasınız. Ancak ben sizden çok uzaklardayım. Bahar tekrar geliyor, hasat vakti yaklaşıyor. Sizden ayrıyım ve fasulyelerin (bana duyduğunuz özlemin) ne kadar büyüdüğünü bilemiyorum. Sadece sizin bir arada olduğunuzu ve onları toplayabildiğinizi umut ediyorum. Bu kırmızı fasulyeler arkadaşlığımızın sembolüdür.

Wang Wei, üstü kapalı bir anlama yer vermeden arkadaşlarına duyduğu özlemi dile getirmektedir. Artık ülkenin güneyinde olmadığını, orada hasret tohumlarının ekildiğini söylemektedir. Arkadaşlarının kendisini ne kadar özlediğini bilmediği için bu hasret tohumlarının ne kadarının yetiştiğini tahmin edemediğini aktarmaktadır. Son iki mısrada ekilen hasret tohumlarının hasadı ne kadar çok olursa arkadaşlarının da ona duyduğu özlemin o kadar fazla olduğunu ifade etmektedir. Bu sebeple kırmızı fasulyenin, hasret tohumu anlamından yola çıkarak hasat edilen kırmızı fasulyeleri arkadaşlıklarının sembolü olarak nitelemektedir.

Vadide Kuş Cıvıltılar

Bahar çiçekleri huzurla dökülür,

Gece sessiz, dağlar boş.

Ayın doğuşu dă̆ kuşlarını ürkütür,

Vadiden bahar geçtiği zaman.
鸟鸣涧

人闲 8 桂花 9 落,

夜静春山空。

月出惊山鸟,

时鸣春涧中。

Şiirin her bir satırında farklı doğal nesnelere işaret edilmektedir. Bahar çiçekleri, sessiz geceler, ayın doğuşu; huzurlu bir ortamın varlığını görselleştirmek için kullanılmıştır. Bahar çiçekleri olarak tercümesi yapılan Guihua, gür yaprakları ve çiçekleri olan bir bitkidir. Her daim yeşil kalabilen bu bitkinin çiçeklerinin ya da yapraklarının döküldüğünü fark etmek için özellikle dikkat etmek gerekmektedir. Şair bu ayrıntı ile çiçeğin ve yaprakların düşüşündeki sesi, dokunma hissini, bitkiden yayılan kokuyu ortaya çıkarmayı amaçlamıştır. Renxian kelimesi ise anlamı pekiştirmek için kullanılmıştır. Bu satır insanların herhangi bir olumsuz faaliyette bulunmadığı bir toplumu ve şairin iç huzurunu ifade etmektedir. Bu durum aynı zamanda Tang Hanedanlığının istikrarlı ve düzenli yönetimini nitelemektedir.

\footnotetext{
${ }^{7}$ Kırmızı fasulye: Çin'in güney bölgesinde yetişen bir bitkidir. Bezelye gibi yuvarlaktır ve pürüzsüz taneleri vardır. Parlak kırmızı renktedir.

${ }^{8}$ Renxian (人闲): Kelime, insanların herhangi bir faaliyette bulunmadığı, sessiz, huzurlu bir ortamı ifade etmektedir.

9 Guihua (桂花): Genellikle bahar mevsiminde çiçek açan, dört mevsim yeşil yapraklı bir bitkidir. Bilimsel adı Osmanthus fragrans'dır. Kökeni Yunancaya dayanan bu isimde -osm- koku, -antos- ise çiçek anlamına gelmektedir. Bitkiye dünyanın farklı ülkelerinde tatlı zeytin, çay zeytini, kokulu zeytin ve kokulu çay zeytini gibi isimler verilmektedir. Kelime şiirin akıcılığına uyum sağlaması için "bahar çiçekleri” şeklinde tercüme edilmiştir.
} 
"Ayın doğuşu ürkütür dağ kuşlarını" mısrası, huzurlu sosyal atmosferi işaret etmektedir. Sessiz ormanlık bir alanda çıkabilecek en küçük bir ses kuşları ürkütmeye yeterlidir. Ancak o kadar küçük bir ses bile yoktur ve kuşlar aniden çıkan ay ışığı ile ürküp kanat çırpmışlardır. Şair, şiirini kaleme aldığı dönemde toplum huzurunu bozacak, kargaşa yaratacak bir olumsuzluk olmadığına vurgu yapmaktadır.

Wang Wei, doğa olayları temalı şiirlerinde sessiz ve huzurlu bir ruh hali ortaya koymayı seven bir şairdir. Çiçeklerin açılıp dökülmesi, kuş sesleri, nehirlerin akması, mevsimlerin değişmesi gibi olaylar şiirlerine canlılık kazandırmaktadır. Sürekliliği olan bu olaylar okuyucuda doğayı dinleme ve huzur hissi uyandırmaktadır. Anlatımdaki sadelik şiirlerine akıcılık katmakta ve anlaşılırlığını kolaylaştırmaktadır.

\section{Meng Haoran (孟浩然)}

689-740 yılları arasında yaşamış bir şairdir. Xiangyang da doğmuştur. (Günümüzde Hubei Bölgesi içerisinde yer almaktadır). Soylu bir aileden gelmeyen Meng Haoran, gençlik döneminde dünyayı tanımaya çok heveslidir ve uzun yıllar bu amaç doğrultusunda hareket etmiştir. Ancak yaşadığı hayal kırıklıkları ve acı tecrübelerden sonra kendi içsel dünyasına dönmeye karar vermiş ve Lu Men Dağında inzivaya çekilmiştir. Kırk yaşına geldiğinde başkent Chang-an'a gitmiştir. Memurluk sınavına girmiş ama başarılı olamamıştır. 737 yılında şair Zhang Jiuling'in davetiyle Jing Zhou'ya gitmiştir. Ancak burada da uzun süre kalmamıştır. Bir yıl sonra, 738 yılında, doğduğu yer olan Xiangyang'a geri dönmüştür. 740 yılında da hastalanarak hayatını kaybetmiştir (Qing, 2009, s. 22-23).

Meng Haoran'ın bir diğer ismi de Meng Shanren'dır (孟山人). Klasik Çin Şiirinde doğa olayları temalı şiirlerde önde gelen şairlerden bir tanesidir. Meng Haoran, yaşadığı dönemin ne çok önemli ne de çok sıradan şairlerinden birisi olarak nitelendirilmektedir. Tang Hanedanlığ dönemi şairlerinden Li Bai ve Du Fu gibi başarılı şairler ile karşılaştırıldı̆̆ında çok önemli bir şair olarak görülmemektedir. Li Bai ve Du Fu ile kıyaslandığında Meng Haoran'ın ortaya koyduğu eserler; sayı bakımından azdır ve nitelik bakımından üstün değildir. Ancak, Tang dönemi Wang Meng Şiir Okulunun kurucularından biri olması ve şiirlerinin günümüzde dahi etkili olması ile sıradan bir şair olarak da görülmemektedir (Li, 1989).

Meng Haoran'ın beş imden oluşan şiirleri çoğunluktadır. Şiirleri, mısra olarak uzun değildir. Şiirlerinin temaları genel olarak; dağlar, ırmaklar, bahçeler, tarım alanları ve doğa olaylarıdır. Akıcı bir dil kullanarak şiirlerini yazmıştır. Bu da şiirlerin anlaşılırlığını kolaylaştırmaktadır. Onun şiirlerinin Klasik Çin şiirine etkisi ve günümüz modern Çin şiirine yansımaları çok büyüktür. Meng Haoran'ın Beş İmli Dört Mısralı Şiir türüne göre yazılmış ve doğa olayları temalı şiirlerinin en güzel örnekleri şunlardır;

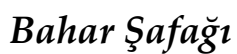

Baharda uykular şafă̆a erişir,

\section{春晓}

春眼不觉晓, 
Kuş civultıları her yerde işitilir.

Gece rüzgâr ve yă̆mur sesleri,

Kim bilir şafă̆a kaç çiçeği soldurur.
处处闻啼鸟。

夜来风雨声,

花落知多少。

Şiirde bahar kuşlarının ötüşleri, rüzgâr ve yağmur sesleri, çiçeklerin açılışı seslendirilerek anlatılmıştır. Okuyucuya, duyuyormuş izlenimi oluşturulmaya çalışılmıştır. Şairin, şiiri yazarken ki düşüncelerini okuyucunun hayal etmesini sağlamak için anlatımda somut nesneler ağırlıklı olarak kullanılmıştır. Hislerin görsel bir manzaraya dönüştürülmesi amaçlanmıştır. Doğal ve sade bir dille yazılmıştır ve anlaşılması kolaydır. Anlatımdaki sadeliğin sebebi, okuyucuyu şiirin içine çekme çabasıdır. Şiir okuyucuda ister istemez şairle birlikte bahar sabahına uyanıyormuş, çiçeklerin açılıp solmalarını ve baharın renklerini seyrediyormuş gibi bir his uyandırır.

Meng Haoran, Bahar Şafağı başlıklı şiirinde şunu dile getirmektedir; Bahar gecelerinde uykuya dalarım, göz açıp kapayana kadar gün doğar. Her yerde kuş cıvıltılarını duyarım. Gece rüzgârın getirdiği yağmur sesleri çalınır kulağıma. Bu seslerin kaç tane çiçeği soldurduğunu bilmem.

Şiirde Meng Haoran'ın doğa olaylarından yola çıarak gençliğinde yaşadığı hayal kırıklıklarını anlatmaya çalıştığı görülmektedir. Gençlik döneminde dünyayı tanımaya hevesli olduğu bilgisine çalışmanın daha önceki kısımlarında yer verilmiştir. Baharda uykular şafağa erişir mısrasında, gençlik hayallerinin artık bir rüya olduğunu ve son bulduğunu anlatmaktadır. Kuş cıvıltıları her yerde işitilir mısrasında ise gezdiği birçok yer olduğuna vurgu yapmaktadır. Üçüncü mısrada gençlik döneminin son bulduğundan, hayallerini gerçekleştiremediği için umutsuzluk içerisinde kaldığından bahsetmektedir. Rüzgâr ve yağmur yaşadığı zorlukları simgelemektedir. Son mısrada ise umutsuzluğunu, hayatındaki belirsizliği dile getirmektedir. Çiçekler hayallerini ve beklentilerini simgelemektedir. Çiçeklerin, hayal kırıklıklarına yenik düştüğünü anlatmaktadır.

\section{Luoyang'a Gidip Yuan Shiyi'yi Bulamamak}

Yetenekle buluşmak için gider Luoyang'a,

Ama çoktan sürgün edilmiştir Jiangling'e

Orda erik çiçekleri erken açar derler,

Nasıl kuzeydekiler kadar güzel olsun ki?

\section{洛中访袁拾遗不遇}

洛阳访才子，

江岭作流人。

闻说梅花早,

何如北地春。

Meng Haoran bu şiirini arkadaşı Yuan Shiyi ile görüşmek için doğum yeri olan Xiangyang'dan Luoyang'a gittiğinde yazmıştır. Şiir; genel olarak mutluluk, umut, hayranlık, hasret, üzüntü, hayal kırıklığı gibi karmaşık duyguları ve karşıt durumları içermektedir. Şiirin ilk satırında yer alan "yetenek" kelimesi Yuan Shiyi' yi nitelemek için kullanılmıştır. Bu durum aynı zamanda Meng Haoran'ın arkadaşına duyduğu hayranlığı da göstermektedir. Yuan Shiyi'nin yaşadığı Luoyang, Tang Hanedanlığının refah seviyesi yüksek, önemli siyasi ve kültürel merkezlerinden bir tanesidir. İkinci satırda geçen Jiangling ise Dagengling'i ifade etmektedir. Burası, Lingnan bölgesinde bulunan sıradağı oluşturan beş tepeden bir tanesidir. Buraya aynı 
zamanda “erik çiçeği tepesi” anlamına gelen Meiling' de [梅岭] denilmektedir. Tang Hanedanlı̆̆1 döneminde sürgün edilen kişiler bu bölgeye gönderilmektedir. Yetenekli ve sürgün edilen tabirleri ile Luoyang ve Jiangling şehirleri, şiirdeki karşıtlıkları ifade etmek için kullanılmıştır. Şaire göre; yetenek kolay elde edilebilecek bir özellik değildir. Yöneticilerin tekrar tekrar yararlanabileceği bu kişileri sürgünle cezalandırılması yönetimdeki tutarsızlığı vurgulamaktadır. Luoyang ve Jiangling'in nitelik olarak birbirinden farklı şehirler olduğunun anlatılması, iki şehrin toplum yaşamı arasındaki farklılığı da ortaya koymaktadır. Bu iki mısradaki zıtlık çok güçlü ve belirgindir, aynı zamanda şairin zihnindeki adaletsizlik kavramına da vurgu yapmaktadır.

Jiangling, coğrafi özelliklerinden dolayı nemli bir havaya sahiptir. Bu özelliğinden dolayı erik çiçekleri vaktinden önce açmaktadır. Şair, son iki satırda bu duruma vurgu yapmakta ve yine Jiangling ile Luoyang'ı karşılaştırmaktadır. Şair Jiangling'de erik çiçeklerinin vakitsiz açtığını söyleyerek, buranın eğitimli birisi için uygun bir yer olmadığını anlatmaktadır ${ }^{10}$. Son satırda hem kendi fikrini söylemekte hem de soru cümlesi kullanarak okuyucuyu da kendi fikrine yaklaştırmaya çalışmaktadır.

\section{DEĞERLENDİRME}

Tang Hanedanlığı döneminde şiir, günümüzde olduğundan çok farklı anlamlara sahiptir. Şiir, sadece bir sanat dalı değil aynı zamanda bir iletişim aracıdır. Bazı yazarlar ziyarete gittikleri kişilere ulaşamadıkları zaman kısa şiirler yazarak o kişiye iletilmesi için bırakmakta ve bıraktığı şiirinin cevabını yine aynı şekilde şiirle almaktadır. Bu durum şiirinin günlük hayatla bütünleştiğini göstermektedir. Çin yazısının resim yazısı olma özelliği, şiire anlamsal ve edebi kimliğinin dışında görsel bir sanat kimliği kazandırmaktadır. Çin hat sanatı da bu görselliği pekiştirmektedir. Çalışmada yer alan şairlerden Wang Wei başta olmak üzere pek çok şairin aynı zamanda ressam da olması şiir ve resimin iç içe olmasını sağlamıştır.

Tang döneminde birçok farklı türde şiir yazılmıştır. Bu türlerden Beş İmli Dört Mısralı Şiir çalışmanın odak noktasıdır. Milattan önce iki yüzlü yıllara dayanan bir geçmişe sahip olan bu şiir türü en verimli sürecini Tang Hanedanlığı döneminde yaşamıştır. Anlatımının sade ve anlaşılır olması, kelimelerin çok fazla yan anlam içermemesi bu şiir türünde ortaya konulan eserlerin sayısının artmasını sağlamıştır. Genellikle doğa olayları temalı eserler ortaya konulmuştur. Araştırmacı Xing doğa olaylarını konu alan şiir türleri için "Şiir aklı temizler, ruhu arındırır, doğanın gizemlerini ve güzelliklerini algılamamıza yardımcı olur" demektedir (Xing, 1976, s. 41).

Çalışmada çevirilerine yer verilen ve anlamsal olarak incelenen şiirlerin hepsi dört mısradan oluşmaktadır ve doğa olayları temalıdır. Şairlerin anlatmak istedikleri konular birbirinden farklıdır ama anlatımda benzer ögeler kullanmışlardır. Şairler, şiirlerin anlaşılırlığını kolaylaştırmak için akıcı ve daha az gösterişli bir şiirsel üslubu tercih etmişlerdir. Meng Haoran'a

\footnotetext{
${ }^{10} \mathrm{Bu}$ mısralarda yer alan erik çiçeğinin Çin kültüründe özel bir yeri vardır. Birçok anlamının yanı sıra başarılı öğrenciler yetiştiren eğitimcileri ifade etmek için de kullanılmaktadır. “(桃李满天下) Dünyanın her yeri şeftali ve erik ağaçlarıyla dolu” sözü bir öğretmenin yetiştirdiğini değerli birçok öğrencisi olduğunu vurgulamak için kullanılmaktadır (Ceylan, 2018). Hem hocaya hem de öğrencilerine övgü vardır.
} 
kıyasla Wang Wei şiirlerinde günlük yaşamın ötesinde ulaşılmak istenen hayali bir dünya sunmaktadır ve sessiz bir inziva hali ortaya çıkarmaya çalışmaktadır. Meng Haoran ise kendi yaşamından yola çıkarak daha çok eleştirel şiirler kaleme almıştır.

\section{KAYNAKÇA}

Yu Tai Xin Yong (玉台新咏). (2018, Kasım 22). Kasım 22, 2018 tarihinde ctext.org: https://ctext.org/wiki.pl?if=gb\&chapter=946748\&remap=gb adresinden alınd 1

Aktaş, Ş. (2017). Toba-Wei (Tabgaç) Devleti Orta Asya Türk Tarihindeki Yeri ve Önemi. Toroslardan Tanrı Dă̆larına Genel Türk Tarihine Adanmış Bir Ömür (s. 285-300). içinde İstanbul: Türk Dünyası Araştırma Vakfı.

Ceylan, F. E. (2018). Türkiye'nin Tek Sinoloji Profesörü Prof. Dr. Bülent OKAY. Çin Medeniyeti: Tarih, Kültür, Edebiyat, Felsefe "Prof. Dr. Bülent OKAY'ın 35. Meslek Yil Anısma" (s. 11-32). içinde İstanbul: Kesit Yayınları.

Eberhard, W. (1995). Çin Tarihi. Ankara: Türk Tarih Kurumu.

Hung, H. M. (2013). Li Shi Min, Founding The Tang Dynasty The Strategies That Made China The Greatest Empire In Asia. New York: Algora Publishing.

Kırilen, G. (2010). Tang Dönemi Şiiri: Üç Şiir Üç Şair; Li Bai Lu Zhaolin ve Shi Juanwu. Ankara Üniversitesi Dil ve Tarih-Coğrafya Fakültesi Dergisi, 50(2), 221-229.

Li, J. (1989). Meng Haoran Shige Yishu Fengge de Zai Sikao. Xinan Daxue Xuebao (Shehui Kexue Ban), 13(3), 79-87.

Luo, Y. (2011). A Concise History of Chinese Literature. Leiden-Buston: BRILL.

Pamuk Öztürk, N. (2016). Tang Dönemi Şiiri ve Bai Juyi (白居易). Current Research in Social Sciences, 2(2), 79-85.

Qing, G. (2009). Tang Shi Sanbai Shou. Pekin: Çin Kültürü yayınevi.

Sun, C. (2007). Sui Tang Wudai Wenhua Shi. Shanghai: Doğu Yayınları Merkezi.

Taşağıl, A. (2017). Gökbörünün İzinde Kadim Türklerin Topraklarında. İstanbul: Kronik Kitap.

Ünal Chiang, G. (2016). Çin Modern Edebiyatı Deneme Eserleri Seçkisi. İstanbul: Kesit Yayınları.

Ünal Chiang, G. (2017). 4 Mayıs Hareketi Ve Çin Edebiyatında Modernleşme: Modern Çin Edebiyatının Öncüsü Zhu Ziqing ve Unutulmaz Eseri “Beiying”. Folklor/Edebiyat, 23(89), 41-58.

Xing, G. (1976). Potery and Music. Chinese Culture, XVII(2), 41-45.

Xu, L. (2003). Tang Chao Wenhua Shi. Shanghai: Shanghai Fudan Üniversitesi Yayınevi.

Zhang, L. (2007). Yu Tai Xin Yong. Shanghai: Shanghai Tarihi Yayınlar Yayınevi.

Zhu, Q. (2011). Kan De Jian De Guren Shenghuo. Pekin: Çin Kültürü Yayınevi. 
TÜRK BILİMKURGU

EDEBIYATI

VE ARKETIPLER

DR. VELİ UĞUR

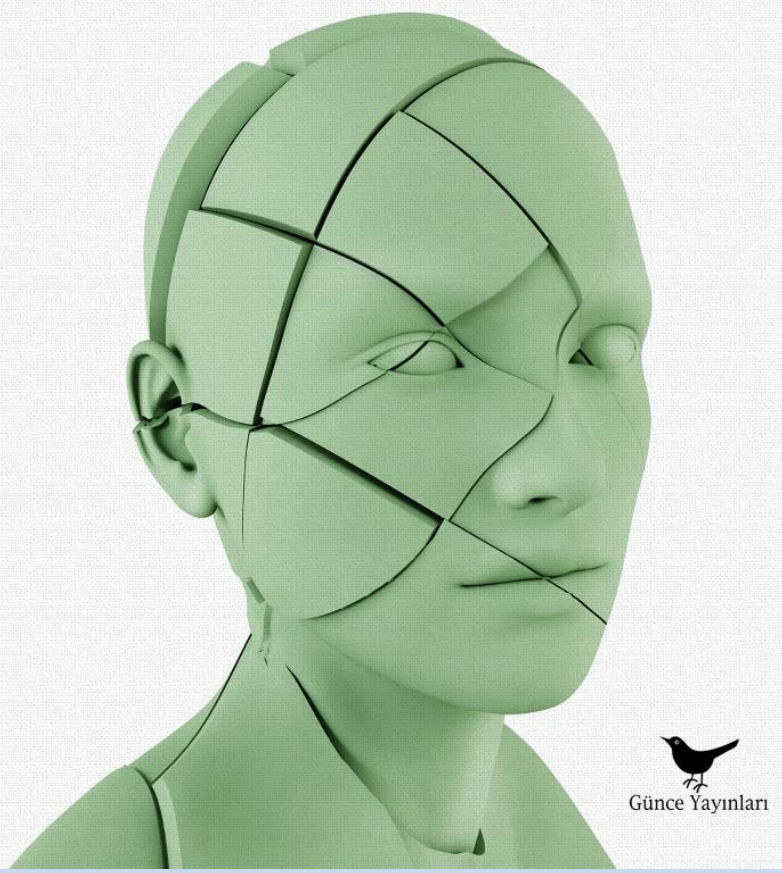

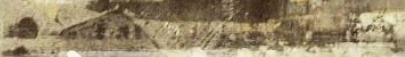

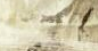

Jktdl| Џill|

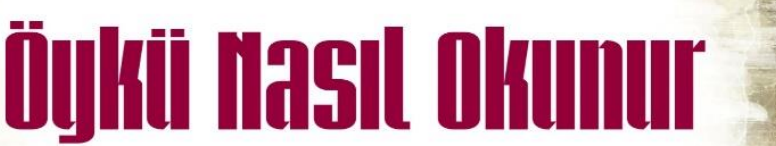

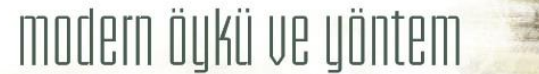

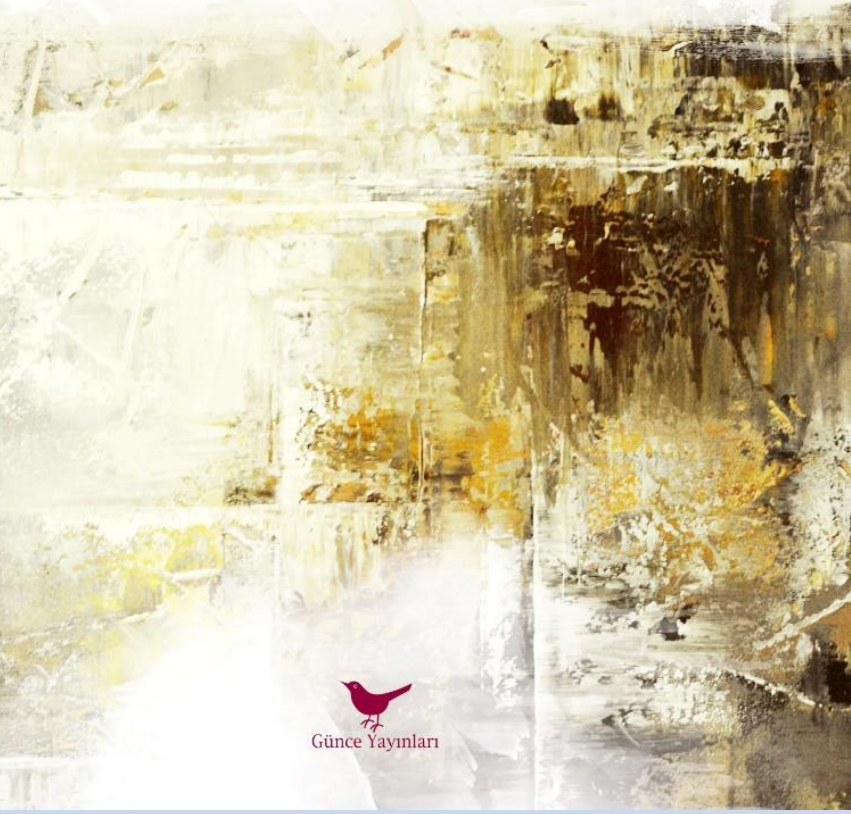

\section{Yazma Sanatı}

Edebivatutn Ebemklusăgu|

Halit Zijya Hilkâyecilliğinde Renklerin Dili

\section{MAKSUT Yit̆̈itBAŞ}

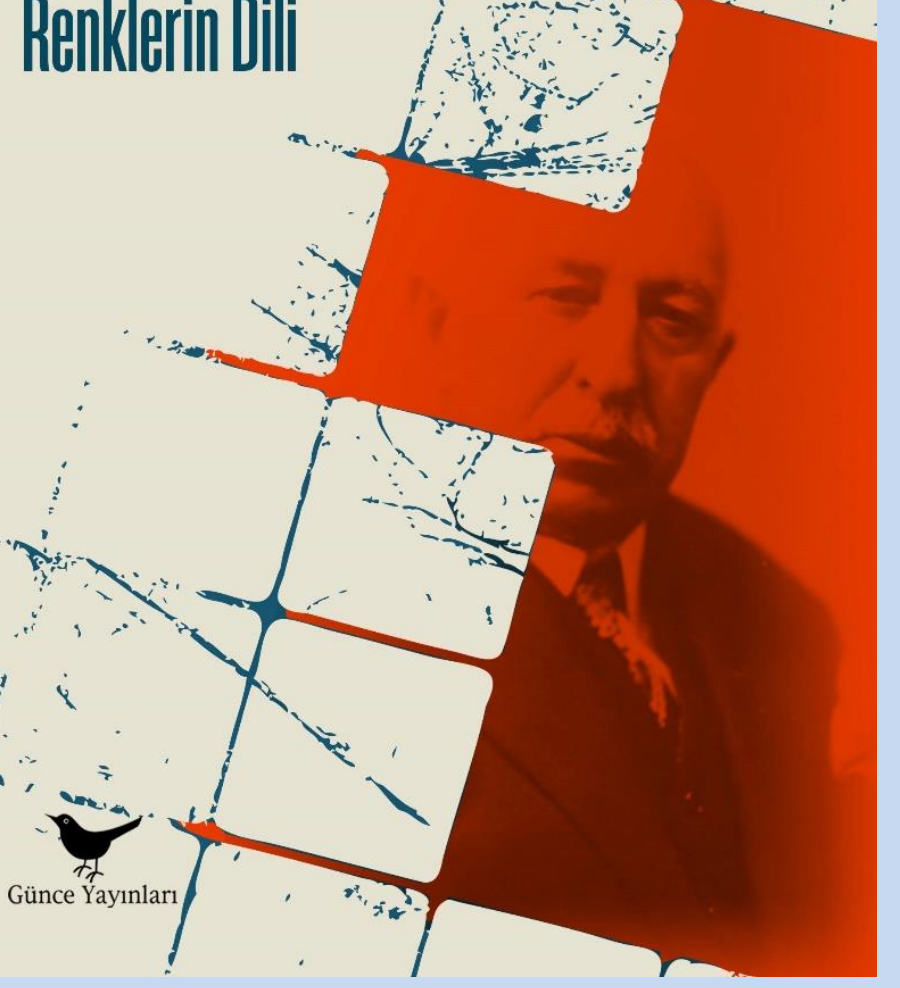

Türkçe Doğru ve Etkili Yazma Teknikleri

Prof. Dr. Önder Göçgün 